Title page

\title{
Predictive value of urethra mobility before sub-urethra tape procedure for urinary stress incontinence in women
}

\section{Authors}

Xavier Fritel, MD

Khalid Zabak, MD

Alain Pigné, MD

Fabien Demaria, MD

Jean-Louis Bénifla, MD

\section{$\underline{\text { Institution }}$}

Service de Gynécologie et Obstétrique, Hôpital Rothschild AP-HP,

Université Pierre-et-Marie-Curie, Paris, France.

\section{Correspondence}

Dr Xavier Fritel

Service de Gynécologie et Obstétrique, Hôpital Rothschild,

33, boulevard de Picpus, 75571 Paris cedex 12, France.

Telephone: +33.140.193.726,

Fax: +33.140 .193 .758$

E-mail: xavier.fritel@rth.ap-hop-paris.fr

Running-head:

Predictive value of urethra mobility before sub-urethra tape procedure

Key-Words:

urinary stress incontinence; surgical mesh; urodynamics; female. 


\section{Abstract}

Purpose: To determine whether preoperative urethra mobility is able to predict suburethra tape procedure outcome for women with urinary stress incontinence.

Materials and methods: This retrospective study included 78 women who underwent a complete work-up with preoperative standing urethrocystography. Proximal urethra support was assessed on lateral urethrocystograms taken at rest and at strain. The two images were anatomically superimposed and the angle formed by the 2 proximal urethra axes defined urethra mobility. Surgical outcome was assessed by negative stress and pad tests.

Results: Median follow-up was 9 months (1-37) and the objective success rate was $85 \%(66 / 78)$. Median rotation of the proximal urethra was $67^{\circ}$ without prior surgery for incontinence, $33^{\circ}$ with 1 previous procedure and $28^{\circ}$ with $\geq 2$ procedures $(p<0.0001)$. The success rate was $97 \%(29 / 30)$ when urethra mobility exceeded $60^{\circ}$ versus $86 \%(18 / 21)$ for mobility between 30 and $60^{\circ}$, and $70 \%(19 / 27)$ when it was $<30^{\circ}(p=0.023)$. The success rate was $96 \%(26 / 27)$ without prior surgery for incontinence versus $84 \%(31 / 37)$ when 1 unsuccessful procedure had been performed, and $64 \%(9 / 14)$ with $\geq 2$ surgical failures $(p=$ 0.026). Age at surgery, menopausal status, mixed incontinence, body mass index, parity, overactive bladder and low maximal urethral closure pressure had no significant prognostic value

Conclusions: The sub-urethra sling procedure takes advantage of urethra mobility to avoid leakage. The more the proximal part of the urethra moves under stress, the better the continence achieved. Risk factors for failure are poor mobility of the proximal urethra and previous surgery for incontinence. 


\section{Introduction}

Classical procedures for urinary stress incontinence (retropubic suspension or sling) suspend the bladder neck to assure continence. The tape described by Ulmsten is no longer placed under the bladder neck but under the middle of the urethra. ${ }^{i}$ Some preliminary reports suggested that the mechanism of continence for the tension-free vaginal tape (TVT) is independent of correction of the proximal urethra hypermobility. Klutke et al. found similar Q-tip values before and after TVT (mean $42.75^{\circ}$ before versus $31.75^{\circ}$ after). ${ }^{\text {ii }}$ Atherton and Stanton used ultrasound to compare bladder neck mobility: after colposuspension the rotation during Valsalva maneuver was reduced (mean $2^{\circ}$ postoperatively versus $46^{\circ}$ preoperatively); following TVT, the difference did not reach significance (mean $29^{\circ}$ versus $40^{\circ}$ ). ${ }^{\text {iii }} \mathrm{We}$ postulated that the preoperative state of bladder neck mobility could predict the outcome. Our hypothesis was that continence after surgery would be achieved because the upper part of the urethra would rotate and descend under stress while the middle portion of the urethra would be held in place by the sling. In others words, if the proximal part of the urethra does not move under stress, the sling cannot assure continence. To confirm this hypothesis, we examined the objective outcomes of women who underwent urethrocystography to determine objectively the preoperative mobility of the proximal urethra under stress. 


\section{Materials and Methods}

Among the 275 patients who had a TVT procedure for urinary stress incontinence between January 1998 and December 2000 in our institution, 90 underwent preoperative urethrocystography. The X-rays were lost for 6 patients, 1 died and the postoperative evaluation was incomplete for 5 others. Finally, 78 patients with complete preoperative and postoperative work-up could be evaluated and constituted the study population. Urethrocystography was systematically performed the first year (1998) of our experience with the TVT procedure. At that time, indications were previous incontinence surgery or low urethra mobility evaluated by physical examination.

The preoperative assessment comprised a self-questionnaire, physical examination, pad test, urodynamic study and urethrocystography. Postoperative visits were scheduled 1, 6, 12, 24 and 36 months after the TVT procedure. The postoperative assessment was similar to the preoperative evaluation with a self-questionnaire, pad test, physical examination and urodynamic study.

Physical examination and urodynamic work-up were performed in the lithotomy position with the trunk at $30^{\circ}$ and the thighs flexed at $45^{\circ}$. The patients were given $1 / 2$ liter to drink 1 hour before the test. The urinary stress test was positive when urine was lost upon coughing or Valsalva maneuver. A maximal urethra closure pressure (MUCP) $<20 \mathrm{~cm} \mathrm{H}_{2} \mathrm{O}$ defined intrinsic sphincter deficiency (ISD). Overactive bladder was defined as involuntary detrusor contractions $\geq 15 \mathrm{~cm} \mathrm{H}_{2} \mathrm{O}$ before $300 \mathrm{ml}$ during the filling phase. We used the 20 minute pad test described by Hahn. ${ }^{\text {iv }}$

Bladder-neck mobility was assessed by lateral urethrocystography. The examination is carried out with the patient standing erect after opacification of the urethra and the bladder. A 
first X-ray is taken at rest during a pelvic muscle contraction. A second X-ray is taken at strain during a Valsalva maneuver. The outlines of the urethra and the bladder on both X-rays are then copied, anatomically superimposed onto tracing paper. The mobility of the proximal urethra, defined as the upper half, is evaluated by comparing its position at rest and at strain (figure 1). A line drawn between the middle of the urethra and the bladder neck defines the proximal urethra axis. The angle formed between the two axes at rest and at strain defined proximal urethra mobility. We classified urethra mobility into three categories, $<30^{\circ}, \geq 30$ and $\leq 60^{\circ}$, and $>60^{\circ}$

Objective success was defined as negative stress and pad tests.

Statistical analyzes were performed using bivariate non-parametric tests, chi $^{2}$ or Fisher's exact test for qualitative data, Mann-Whitney or Kruskal-Wallis test for quantitative data. StatView 4.5 software was used for analysis. 


\section{Results}

Median age at surgery was 56 years (34-87). Among the 78 patients, $51(65 \%)$ had undergone at least 1 previous unsuccessful procedure to correct urinary incontinence (table I). Preoperative median proximal urethra mobility was $42^{\circ}(-5$ to +108$)$. It was $<30^{\circ}$ for 21 patients, $\geq 30$ and $\leq 60^{\circ}$ for 27 , and $>60^{\circ}$ for 30 . The relationships between urethra mobility and the patients' characteristics are presented in table II. The number of previous procedures for incontinence was significantly associated with lower urethra mobility. Median rotation of the proximal urethra was $67^{\circ}$ without any prior surgery for incontinence, $33^{\circ}$ with 1 previous procedure, and $28^{\circ}$ with $\geq 2$ procedures $(\mathrm{p}<0.0001$, Kruskal-Wallis test).

Median time needed to complete the procedure was 30 minutes (15-140). For 17 patients, another surgical procedure was associated, 4 vaginal hysterectomies, 14 posterior repairs, 3 sacrospinofixations, 1 anterior repair. Anesthesia was local for 2 , general for 1 and regional for 75 . Surgical complication included 6 bladder perforations $(8 \%)$ and 1 urethra injury. The urethra catheter was removed the day after surgery except for patients with bladder perforation or urethra injury. Thirteen (17\%) patients, who had severe voiding difficulties, required an additional period of catheterization (suprapubic or intermittent catheterization). Patients were discharged a median of 2 days $(0-16)$ postoperatively. No major complication occurred.

Median objective follow-up was 9 months (1-37). The objective success rate was $85 \%$ (66/78). Post-void volume was $>100 \mathrm{ml}$ for $18(23 \%)$ patients. Six patients required further intervention: 2 patients with vaginal mesh erosion underwent resection of the exposed sling (123 and 382 days after the TVT procedure), 1 patient with a bladder stone had lithotripsy (119 days later), 3 patients with persistent voiding dysfunction underwent a stretching of the 
tape using a Hegar sound to push the urethra downwards (14, 15 and 21 days later) as described by Wang and Lo. ${ }^{v}$

According to univariate analysis, factors significantly associated with the objective success rate were previous surgery for incontinence and preoperative mobility of the proximal urethra (table III). The objective success rate was $97 \%$ (29/30) when the mobility of the urethra exceeded $60^{\circ}$ versus $86 \%(18 / 21)$ when it was between 30 and $60^{\circ}$, and $70 \%(19 / 27)$ when it was $<30^{\circ}\left(p=0.023\right.$, chi $^{2}$ test $)$. The success rate reached $96 \%(26 / 27)$ with no previous surgery for incontinence versus $84 \%(31 / 37)$ with 1 previous unsuccessful procedure, and $64 \%(9 / 14)$ with $\geq 2$ surgical failures $\left(p=0.026\right.$, chi $^{2}$ test $)$. For patients with previous surgical failure and urethra mobility $<30^{\circ}$, the success rate was $68 \%(17 / 25)$. The strong association between urethra mobility and previous surgical failure did not allow us to perform a multivariate analysis.

The success rates did not differ significantly for $\mathrm{MUCP}<20$ or $\geq 20 \mathrm{~cm} \mathrm{H}_{2} \mathrm{O}, 80 \%$ $(8 / 10)$ versus $85 \%(58 / 68)$ respectively $(p=0.65$, Fisher test $)$. 


\section{Discussion}

Standing urethrocystography has been used for many years to evaluate urethra and bladder neck mobilities, and is considered the standard examination. ${ }^{\mathrm{vi}}$ Measurement of the urethral angle at rest and at strain has good inter-observer reproductibility. ${ }^{\text {vi }}$ The others methods (Q-tip test, ultrasound and dynamic magnetic resonance imaging) are most often carried out while the subject is lying down, which gives different values than those for a

patient standing erect. ${ }^{\text {vii, viii }}$ It would be informative to know whether urethra mobility measured with a method other than standing urethrocystography would also have a predictive value for TVT outcome.

Our data confirm our hypothesis that preoperative mobility of the upper part of the urethra can predict the objective outcome of the sub-urethra tape procedure. The more the proximal part of the urethra moves under stress, better the continence will be by placing the sling under the middle of the urethra. We advance that the TVT procedure takes advantage of urethra mobility to avoid leakage instead of correcting it. That is the main difference between the sub-urethra sling and the classical procedures that block bladder neck mobility. In our population, the more previous operations the patient had, the less her urethra moved under strain. This strong association between low urethra mobility and previous surgery make reliable logistic regression impossible. Only 2 women undergoing surgery for the first time had low mobility $\left(<30^{\circ}\right)$. For other patients, we do not know if their previous procedure(s) failed because preoperative urethra mobility was low or if urethra mobility was low because surgery had already been performed.

Urethra mobility decreased with increasing age and menopause (table II). Patients whose interventions failed were older than those with successful outcomes, and $92 \%$ of the 
former were menopausal, but this difference was not significant (table III). The small size of our population did not allow us to specify the impact of age and estrogen deficiency in surgical outcome.

Based on our findings, ISD (MUCP $<20 \mathrm{~cm} \mathrm{H}_{2} \mathrm{O}$ ) did not seem to be a prognostic factor for TVT outcome, because objective success rates with or without ISD were similar ( 80 versus $85 \%$, respectively). The referent Scandinavian team had published their long-term results, ${ }^{\text {ix-x }}$ women with low urethral pressure (MUCP $<20 \mathrm{~cm} \mathrm{H}_{2} \mathrm{O}$ ) had lower success rate (74\% cured and $12 \%$ improved) than women with normal urethral pressure $(85 \%$ cured and $11 \%$ improved) but the difference did not reach significance. In the study by KulsengHanssen, there was no difference in postoperative satisfaction and urinary symptoms between women with or without low urethral pressure (MUCP $\leq 20 \mathrm{~cm} \mathrm{H}_{2} \mathrm{O}$ ), but postoperative pad test and stress test values were higher for patients with low urethral pressure. ${ }^{\mathrm{xi}}$ In that study, women with low urethral pressure were older and more of them had suffered bladder perforation during the TVT procedure than women with normal urethral pressure, but differences concerning urethra mobility and previous surgery were not specified. Since poor urethral mobility (or unsuccessful previous surgery) is often associated with low MUCP, Kulseng-Hanssen's findings might reflect the role of low urethra mobility (or unsuccessful previous surgery) rather than ISD. Sphincter competence can be estimated at rest by MUCP and at strain by Valsalva leak point pressure (VLPP). Unfortunately VLPP was not systematically assessed in our study. Further investigations are needed to specify the relationship(s) among VLPP, MUCP, urethra mobility and sub-urethra tape procedure outcome. 
Female continence classically relies on sphincter competence and bladder-neck mobility. Burch's retropubic procedure corrects hypermobility. The prognosis therefore depends on sphincter competence, i.e., the ability of the bladder neck to remain closed when abdominal pressure rises. With the sub-urethra tape procedure, strain produces an obstacle: the more the pressure rises, the more the urethra is bent by the tape, meaning that the prognosis is no longer determined by sphincter competence. The outcome depends rather on urethra mobility, which allows its bending under exertion. The different mechanism of action of the sub-urethra tape procedure in no way puts in doubt the classical physiopathology of female incontinence. 


\section{Conclusion}

Based on our results, we advance that the sub-urethra sling procedure takes advantage of urethra mobility to avoid urine leakage. The more the proximal part of the urethra moves under stress, the better the continence achieved.

We use urethrocystogram findings to advise incontinent women when the Q-tip test value is low or when they had previous surgical failure. A poorly mobile urethra after a previous surgical failure is not a formal contraindication for the sub-urethra tape procedure, as emphasized by the $68 \%$ success rate in this context, but an alternative procedure, like transurethral injection, should be discussed. ${ }^{\text {xii }}$ 


\section{Acknowledgments:}

We are grateful to Armelle Eveillard, Sylvaine Baron and Nathalie Fortez for their help in entering data and handling files. We also thank Janet Jacobson for translating and editing our English text. 


\section{References}

Ulmsten U., Henriksson L., Johnson P. and Varhos G.: An ambulatory surgical procedure under local anesthesia for treatment of female urinary incontinence. Int Urogynecol J, 7: 81, 1996

Klutke J.J., Carlin B.I. and Klutke C.G.: The tension-free vaginal tape procedure: correction of the stress incontinence with minimal alteration in proximal urethral mobility. Urology, 55: 512, 2000

iii Atherton M.J. and Stanton S.L.: A comparison of bladder neck movement and elevation after tension-free vaginal tape and colposuspension. Br J Obstet Gynaecol, 107: 1366,2000

iv Hahn I:: Objective quantification of stress urinary incontinence: a short reproducible, provocative pad test. Neurourol Urodyn, 10: 475, 1991

V Wang A.C. and Lo T.S.: Tension-free vaginal tape, a minimally invasive solution to stress urinary incontinence in women. J Reprod Med, 43: 429, 1998

vi Showalter P.R., Zimmern P.E., Roehrborn C.G. and Lemack G.E.: Standing cystourethrogram: an outcome measure after anti-incontinence procedures and cystocele repair in women. Urology, 58: 33, 2001

vii Gufler H., DeGregorio G., Allman K.H., Kundt G. and Dohnicht S.: Comparison of cystourethrography and dynamic MRI in bladder neck descent. J Comput Assist Tomogr, 24; 382, 2000

viii Handa V.L., Jensen J.K. and Ostergard D.R.: The effect of patient position on proximal urethral mobility. Obstet Gynecol, 86: 273, 1995

ix Rezapour M., Falconer C. and Ulmsten U.: Tension-free vaginal tape (TVT) in stress incontinent women with intrinsic sphincter deficiency (ISD), a long term follow-up. Int Urogynecol J, 12 (supp1 2): S12, 2001 
x Nilsson C.G., Kuuva N., Falconer C., Rezapour M. and Ulmsten U.: Long-term results of the tension-free vaginal tape (TVT) procedure for surgical treatment of female stress urinary incontinence. Int Urogynecol J, 12 (supp1 2): S5, 2001

xi Kulseng-Hanssen S.: Success rate of TVT operation in patients with low urethral pressure. Neurourol Urodyn, 20: 417, 2001

xii Barranger E., Fritel X., Kadoch O., Liou Y. and Pigné A.: Results of transurethral injection of silicone micro-implants for female with intrinsic sphincter deficiency. J Urol, 165: 1619, 2000 


\section{Tables}

$\underline{\text { Table I }}$

Previous unsuccessful continence procedures

\begin{tabular}{lll}
\hline $\begin{array}{l}\text { Previous } \\
\text { procedure(s) }\end{array}$ & Type of procedure & Number \\
\hline None & & 27 \\
One & Retropubic (Burch, Marshall-Marchetti-Krantz) & 28 \\
& Sling (Goebell-Stoeckel, Bologna) \\
& Anterior vaginal repair (Kelly plication) & 5 \\
& Retropubic x 2 & 4 \\
Two & $\begin{array}{l}\text { Retropubic \& transurethral injection (silicone } \\
\text { microimplants) } \\
\end{array}$ & $\begin{array}{l}\text { Anterior vaginal repair \& retropubic } \\
\text { Needle suspension \& sling }\end{array}$ \\
& Retropubic x 3 & 4 \\
Three & & 1 \\
\hline Total & & 78 \\
\hline
\end{tabular}




\section{Table II}

Preoperative characteristics and proximal urethra mobility. Values are medians [range] for continuous variables assessed with the Kruskal-Wallis test and percentages (fraction) for qualitative variables evaluated with the $\mathrm{chi}^{2}$ test.

\begin{tabular}{|c|c|c|c|c|c|}
\hline \multirow{3}{*}{$\begin{array}{l}\text { Preoperative } \\
\text { characteristic }\end{array}$} & \multirow{3}{*}{$\begin{array}{l}\text { All patients } \\
\quad(n=78)\end{array}$} & \multicolumn{3}{|c|}{ Proximal urethra mobility } & \multirow{3}{*}{$\begin{array}{c}\mathrm{p} \\
\text { value }\end{array}$} \\
\hline & & $<30^{\circ}$ & $30-60^{\circ}$ & $>60^{\circ}$ & \\
\hline & & $(n=27)$ & $(\mathrm{n}=21)$ & $(n=30)$ & \\
\hline Age at surgery, years & 56 [34-87] & 59 [46-87] & $55[34-78]$ & $54[34-79]$ & 0.11 \\
\hline Menopausal & $74 \%(58 / 78)$ & $89 \%(24 / 27)$ & $76 \%(16 / 21)$ & $60 \%(18 / 30)$ & 0.043 \\
\hline Body mass index, $\mathrm{kg} / \mathrm{m}^{2}$ & $25[17-40]$ & $24[18-37]$ & $25[20-32]$ & $25[17-40]$ & 0.64 \\
\hline Parity & $2[0-6]$ & $2[0-5]$ & $2[0-6]$ & $2[0-4]$ & 0.33 \\
\hline Previous incontinence surgery & $65 \%(51 / 78)$ & $93 \%(25 / 27)$ & $62 \%(13 / 21)$ & $43 \%(13 / 30)$ & 0.0005 \\
\hline Urge urinary incontinence & $79 \%(62 / 78)$ & $85 \%(23 / 27)$ & $71 \%(15 / 21)$ & $80 \%(24 / 30)$ & 0.50 \\
\hline MUCP, $\mathrm{cm} \mathrm{H}_{2} \mathrm{O}$ & $31.5[5-78]$ & $28.0[5-78]$ & $28.0[12-62]$ & $37.5[15-65]$ & 0.08 \\
\hline Overactive bladder* & $5 \%(4 / 75)$ & $8 \%(2 / 25)$ & $10 \%(2 / 21)$ & $0 \%(0 / 29)$ & 0.26 \\
\hline
\end{tabular}

* Cystometry was missing for 3 patients. 


\section{Table III}

Preoperative risk factors and objective result. Values are median [range] for continuous variables assessed with the Mann-Whitney test, and percentages (fraction) for qualitative variables evaluated with Fisher's exact test.

\begin{tabular}{lccl}
\hline Preoperative risk factors & $\begin{array}{c}\text { Success } \\
(\mathrm{n}=66)\end{array}$ & $\begin{array}{c}\text { Failure } \\
(\mathrm{n}=12)\end{array}$ & $\begin{array}{l}\mathrm{p} \\
\text { value }\end{array}$ \\
\hline Age at surgery, years & $55[34-86]$ & $64[34-87]$ & 0.26 \\
Menopausal & $71 \%(47 / 66)$ & $92 \%(11 / 12)$ & 0.17 \\
Body mass index, $\mathrm{kg} / \mathrm{m}^{2}$ & $24[17-40]$ & $25[20-37]$ & 0.76 \\
Parity & $2[0-6]$ & $2[0-5]$ & 0.24 \\
Previous incontinence surgery & $61 \%(40 / 66)$ & $92 \%(11 / 12)$ & 0.048 \\
Urge urinary incontinence & $77 \%(51 / 66)$ & $92 \%(11 / 12)$ & 0.44 \\
MUCP, cm H $\mathrm{H}_{2} \mathrm{O}$ & $31.5[12-78]$ & $31.5[5-62]$ & 0.76 \\
Overactive bladder* & $3 \%(2 / 64)$ & $18 \%(2 / 11)$ & 0.10 \\
Proximal urethra rotation, degree & $47[0$ to 108$]$ & $24[-5$ to 66] & 0.007 \\
\hline
\end{tabular}

* Cystometry was missing for 3 patients. 


\section{Legends}

\section{Figure 1}

Measurement of proximal urethra mobility: The outlines of the bladder and urethra were traced from lateral urethrocystograms at rest (gray line) and during Valsalva maneuver (black line). A line drawn between the middle of the urethra and the bladder neck defines the proximal urethra axis. The angle formed between the two axes defines proximal urethra mobility $\left(102^{\circ}\right.$ in this example). 
Predictive value of urethra mobility before sub-urethra tape procedure

19

Figure 1

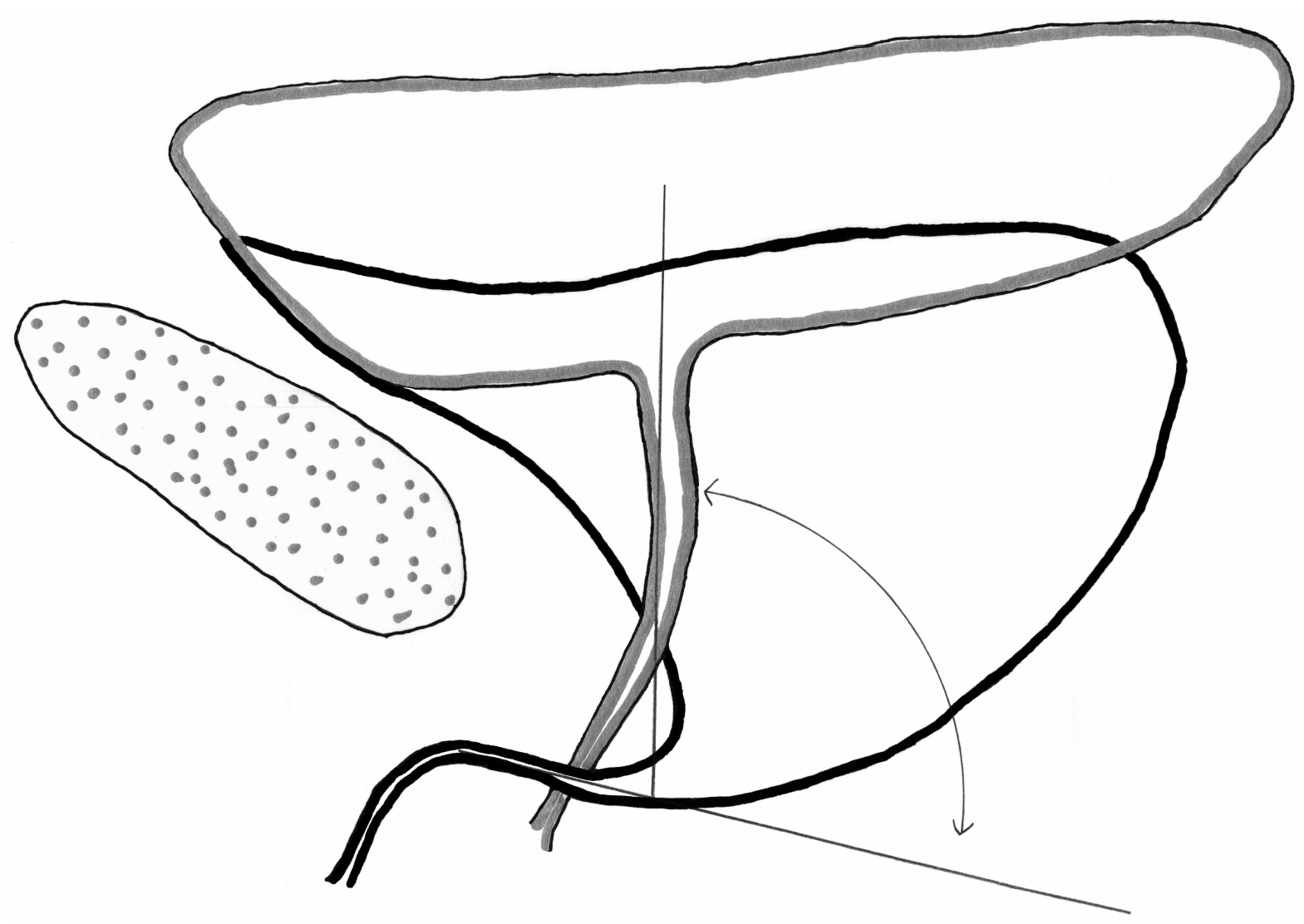

